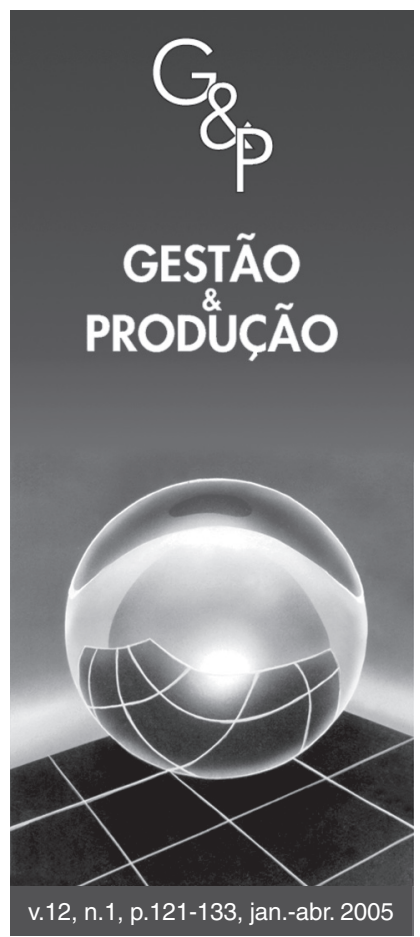

\title{
GLOBALIZAÇÃO E ESTRATÉGIAS COMPETITIVAS NA INDÚSTRIA AUTOMOBILÍSTICA: UMA ABORDAGEM A PARTIR DAS PRINCIPAIS MONTADORAS INSTALADAS NO BRASIL
}

\author{
Enéas Gonçalves de Carvalho \\ Depto. de Economia, \\ Faculdade de Ciências e Letras, UNESP, \\ Rodovia Araraquara - Jaú, km 1, C.P. 174, CEP 14800-901, Araraquara, SP, \\ e-mail: egcarva@uol.com.br
}

Recebido em 01/7/2003

Aprovado em 11/11/2004

Resumo

O presente artigo primeiramente trata do processo de globalização da indústria automobilística internacional. Da mesma forma, o importante papel desempenhado pela introdução de novas tecnologias nessa indústria é também considerado. As mudanças recentes e principais tendências das estratégias competitivas - em particular no tocante à globalização e aos produtos - implementadas por algumas das principais montadoras da indústria automobilística mundial (GM, Ford, Toyota, VW, Fiat) são também examinadas. Por fim, são considerados os planos internacionais e o mercado interno brasileiro.

Palavras-chave: indústria automobilística brasileira, globalização, novas tecnologias na indústria automobilística, estratégia competitiva, estratégias de produtos e P\&D.

\section{Introdução}

O objetivo deste artigo é explorar as relações entre: 1) o processo de globalização da indústria automobilística internacional; 2) as estratégias competitivas implementadas recentemente pelas principais montadoras automobilísticas - especialmente as estratégias de produtos e de P\&D (Pesquisa e Desenvolvimento) -; e 3) o seu respectivo desempenho no mercado brasileiro de automóveis. A hipótese de trabalho é que, em um contexto de aprofundamento da globalização setorial, as estratégias competitivas locais e o respectivo desempenho das filiais no mercado brasileiro estão crescente e fortemente condicionados às estratégias competitivas globais adotadas pelas matrizes. Para o presente artigo, foram selecionadas as seguintes montadoras: General Motors (GM), Ford, Volkswagen (VW), Fiat e Toyota. A escolha destas montadoras resultou de um critério que levou em conta simultaneamente a importância delas no mercado interno brasileiro, a relevância internacional e a exiqüibilidade da pesquisa.

Este artigo é composto de cinco itens além desta introdução. No item II, foram feitas: 1) uma breve caracterização do processo de globalização deste setor; e também 2) uma breve síntese dos principais aspectos relativos à introdução de novas tecnologias na indústria automobilística. No item III, procurou-se fazer: 1) um resumo das principais estratégias competitivas implementadas recentemente pelas montadoras no âmbito internacional; e também 2) uma avaliação do desempenho destas nos principais mercados internacionais. No item IV, buscouse apontar as linhas gerais das estratégias competitivas mais importantes adotadas recentemente pelas principais montadoras instaladas na indústria automobilística brasileira. No item $\mathbf{V}$, procurou-se mostrar as relações entre as estratégias de produtos implementadas, nos anos re- 
centes, pelas filiais das montadoras instaladas no Brasil e o seu respectivo desempenho no mercado doméstico de automóveis. No item VI, destacaram-se os resultados obtidos neste trabalho.

\section{Globalização e as novas tecnologias na Indústria automobilística}

A globalização da indústria automobilística tem sido caracterizada: 1) pela concentração da produção, das vendas e do comércio no interior dos principais mercados da OCDE (Organization for Economic Co-Operation and Development); 2) pelo "crescentemente importante papel das subsidiárias externas e do IED (Investimento Externo Direto), ligando as empresas e as regiões, reforçado pelo bastante elevado nível de comércio intra-firma" (Vickery, 1996); e 3) pela emergência de novas formas de organização da produção que dependem crescentemente das networkings e das alianças intra e inter-regional e/ou nacional (Freyssenet e Lung, 1997; Sturgeon e Florida, 1999; Hatzichronoglou, 1999; Humphrey et al., 2000; OECD, 2001).

Está última tendência é resultante, por um lado, da intensificação da concorrência no âmbito desta indústria e da conseqüente pressão por um maior grau de coordenação das atividades produtivas e organizacionais entre as matrizes e as redes de empresa afiliadas e, por outro, pelas novas possibilidades tecnológicas viabilizadas pela introdução das novas tecnologias - especialmente pelas técnicas resultantes da convergência entre os novos sistemas de telecomunicações (por satélite e a cabo) com as tecnologias de informatização (Vickery, 1996; Hatzichronoglou, 1999; Carvalho, 2003).

Inegavelmente, uma das características mais marcantes do processo de globalização na indústria automobilística é o concomitante processo de integração organizacional e do sistema produtivo que tem sido levado a efeito pelas montadoras nesta etapa dos seus respectivos movimentos de internacionalização. No caso das filiais brasileiras das montadoras internacionais, este processo de intensificação da integração com as respectivas matrizes tem sido, de uma forma geral, caracterizado também - paralelamente à modernização da linha de produtos, dos processos produtivos e da introdução de inovações organizacionais (consórcio modular, condomínio industrial, etc.) - pela perda de graus de autonomia relativa, uma vez que a maior integração ao sistema produtivo tem como uma das contrapartidas um grau mais elevado de sintonia e comprometimento com as estratégias e com os programas produtivos estabelecidos pelas respectivas matrizes. Mas o maior nível de integração comporta, entretanto, variações quanto à forma, que pode ser mais ou menos ativa (Vickery, 1996; Humphrey et al., 2000; Carvalho, 2003).
Se, por um lado, o avanço do processo de globalização da indústria automobilística apresenta uma dimensão que acentua a convergência de certas características do comportamento das montadoras, por outro, permanecem distintos vários aspectos como, por exemplo, as trajetórias de internacionalização das montadoras ocidentais e japonesas. E estas diferenças não parecem ser apenas geográficas e/ou decorrentes de momentos históricos distintos, mas parecem ter também raízes em processos de desenvolvimento e em capacidades competitivas de naturezas distintas (Fujimoto, 1997; Fujimoto, 1999; Carvalho, 2003).

De forma análoga, as respostas das montadoras ocidentais ao assim chamado 'desafio japonês' não têm sido homogêneas nem no tempo, nem no espaço, nem quanto à forma das estratégias implementadas. Em boa medida, as diferentes respostas adotadas em face do avanço dos fabricantes japoneses resultaram de percepções distintas, por parte das montadoras ocidentais, com relação às novas técnicas desenvolvidas pela Toyota e aos fatores da sua maior eficiência relativa. Da mesma forma, também tiveram importância na escolha das estratégias implementadas as avaliações das possibilidades e da melhor forma para tentar introduzir as novas técnicas, assim como as distintas circunstâncias e as diferentes capacidades de cada uma das principais montadoras - inicialmente das norte-americanas e depois das européias (Fujimoto, 1999; Fine et al., 1996; Carvalho, 2003).

No que se refere às novas tecnologias na indústria automobilística - excetuando-se, é claro, as formas alternativas de propulsão (motores elétricos, híbridos e células de combustível) -, a eletrônica e a tecnologia de informação são indiscutivelmente as variáveis-chave. Como muitos outros setores, a indústria automobilística está expandindo rapidamente a utilização de sistemas e de componentes eletrônicos. Praticamente todas as funções dos autoveículos modernos sofisticados já são controladas e/ou viabilizadas pela eletrônica embarcada. E a tendência em curso parece ser a crescente difusão destes controles eletrônicos para os veículos menos sofisticados, em função da utilização cada vez mais ampla da eletrônica embarcada como arma competitiva e do barateamento relativo dos seus custos de produção (McAlinden et al., 2000; PNGV: Seventh Report, 2001).

Com relação à evolução futura da tecnologia na indústria automobilística internacional, parece razoável considerar a existência, em linhas gerais, de quatro cenários principais (Carvalho, 2003). O primeiro cenário, o menos provável, decorre da suposição de continuidade do atual padrão tecnológico: baseado no motor de combustão interna com aperfeiçoamentos do tipo dos sistemas CIDI (compression-ignition direct-injection) e leanburn; na crescente utilização de componentes eletrônicos (a chamada eletrônica embarcada, aí incluída a telemá- 
tica); na introdução de novos materiais e na intensificação do uso da internet. Este primeiro cenário não parece ser, entretanto, compatível com as exigências previstas nas normas regulatórias relativas à utilização mais eficiente dos combustíveis e, em especial, à eliminação da emissão de poluentes, como, por exemplo, a 'lei 2004' já adotada pelo estado da Califórnia e por vários outros da região nordeste dos E.U. (McAlinden et al., 2000; PNGV, 2001).

O segundo cenário, que parece despertar grande atenção da Toyota, corresponde à possibilidade de que no futuro os consumidores poderiam escolher entre carros movidos a baterias, a células de combustível, a propulsores híbridos e a gás natural, assim como por novos tipos de motores (mais eficientes e menos poluentes) a gasolina e a diesel. Nesta hipótese não haveria uma clara predominância de uma forma de propulsão específica (EIU, 1998a; Fujimoto e Takeishi, 2001)

O terceiro cenário está associado aos veículos híbridos elétricos - um motor elétrico e um motor de combustão interna de combustível fóssil. A tecnologia do motor elétrico e/ou híbrido, embora mais simples e conhecida, parece enfrentar problemas aparentemente de difícil solução - a limitação da capacidade de armazenagem de energia nas baterias e o custo elevado que um veículo com dois propulsores e uma sofisticada bateria necessariamente implicaria (Personal Cars and China, 2003; McAlinden et al., 2000).

O quarto cenário está relacionado à tecnologia das células de combustível. Esta forma de propulsão de veículos é a mais inovadora e sofisticada da próxima geração de tecnologias de powertrain. Até há pouco considerada uma tecnologia aeroespacial, é também aquela que requer as maiores inovações antes de que possa alcançar viabilidade comercial. A tecnologia das células de combustível utiliza-se de reações eletroquímicas contínuas para converter elementos químicos - na maioria dos casos o hidrogênio - diretamente em corrente elétrica, tendo como sub-produto neste caso específico apenas a emissão de vapor d'água. "Essencialmente, o veículo movido pela célula de combustível seria similar, em conceito, ao veículo híbrido em série, com a célula de combustível substituindo o motor de combustão [interna] e a bateria no envio da corrente elétrica para a impulsão [do veículo]" (McAlinden et al., 2000; PNGV, 2001).

Embora não esteja ainda num estágio muito avançado, a tecnologia da célula de combustível parece mesmo ser a mais promissora a médio e longo prazo e a única capaz de viabilizar a exigência de emissão zero de poluentes (Personal Cars and China, 2003; PNGV, 2001; McAlinden et al., 2000). E como o potencial de ganhos e perdas associados à introdução das novas tecnologias é muito amplo - particularmente no caso da tecnologia da célula de combustível -, amplos orçamentos e grandes esforços de pesquisa têm sido despendidos por parte das montadoras que temem ficar alijadas da competição se não dominarem as novas tecnologias (Carvalho, 2003).

\section{As estratégias competitivas recentes das principais montadoras internacio- nais e o desempenho nos mercados mais importantes}

Em linhas gerais, pode-se caracterizar a evolução recente desta indústria, nos principais mercados, pelo avanço da globalização, pelo acirramento da concorrência - aí incluída a intensificação da introdução de novas tecnologias - e pela diminuição dos diferenciais competitivos entre as montadoras mais importantes. Tendo por base este contexto, procurou-se elaborar, a seguir, uma síntese das principais estratégias competitivas implementadas pelas montadoras nos anos recentes bem como uma avaliação dos seus respectivos desempenhos nos principais mercados automobilísticos.

A Ford. Depois de promover uma redefinição das fronteiras da corporação e uma ampla revisão de seus procedimentos internos, a Ford lançou, em 1994, o Ford 2000. Primeiro programa de globalização da indústria automobilística mundial, o Ford 2000 tinha como objetivo fundamental otimizar os recursos mundiais da empresa por meio da eliminação de considerável duplicação de modelos, de componentes e da sobreposição das operações nos E.U.A., na Europa e no resto do mundo. Desta forma, buscava-se reduzir significativamente os custos de desenvolvimento dos produtos bem como ampliar as economias de escala de produção da empresa (Bordenave, 1998; Carvalho, 2003).

Com o lançamento do Focus na Europa no outono de 1998 e nos E.U.A. no final de 1999, o programa Ford 2000 assim como a sua respectiva estratégia do "carro mundial' entraram numa nova fase. O Focus foi o primeiro modelo inteiramente desenvolvido sob a vigência do plano de globalização da Ford e foi, também, a sua segunda tentativa efetiva de desenvolvimento de um modelo que pudesse ser qualificado como um 'carro mundial'. Com uma produção global inicial prevista de 1 milhão de unidades anuais, o Focus permaneceu restrito aos mercados da Europa Ocidental e dos E.U.A. até a segunda metade do ano 2000, quando se iniciou a sua produção nos países em desenvolvimento, nas plantas originalmente destinadas à fabricação do Escort. Cabe destacar, entretanto, que o mercado doméstico norte-americano tem sido, até o momento, o principal obstáculo encontrado pela montadora em sua tentativa de implementação das estratégias de produto do programa Ford 2000 (Bursa et al., 1998; Storey, 1998; Maxton, 1998).

A GM. Apesar da contínua perda de terreno observada nos últimos anos, a GM ainda se mantém como a maior 
montadora do mundo. Não obstante, a maior montadora norte-americana parece decidida a não alterar as linhas gerais da sua estratégia de expansão recente. Do ponto de vista da maior montadora do mundo, globalização significa produzir nos principais mercados. Em sintonia com esta perspectiva, a GM anunciou, no outono de 1998, o seu novo programa de reestruturação global. Com vários pontos em comum com o 'Ford 2000', o plano de globalização da maior montadora norte-americana previa fundamentalmente: 1) a integração das operações automotivas mundiais em um único grupo; 2 ) a redução do número de plataformas de automóveis de 16 para 8; e 3) a adoção da Opel (a subsidiária da GM na Alemanha) como base para a expansão internacional (Bursa et al., 1998; Storey, 1998; Flynn, 1998).

A estratégia de produtos da GM tem se baseado principalmente no conceito de plataforma flexível. O Corsa é um bom exemplo desta estratégia de globalização com racionalização das plataformas. Idealmente adequado para os mercados dos países em desenvolvimento, o Corsa foi também o automóvel mais vendido da GM na Europa em 1996 e 1997, constituindo-se na primeira 'plataforma global' da GM. Tal estratégia não tem impedido, entretanto, que a maior montadora norte-americana abra espaço na sua linha de modelos para a adaptação às demandas regionais, quer seja pelo desenvolvimento de plataformas para os países em desenvolvimento, quer seja pelo desenvolvimento de derivativos específicos (Bursa et al., 1998; Fine et al., 1996; Storey, 1998).

A Toyota. Os objetivos principais do plano de globalização da Toyota eram elevar os lucros operacionais, cortar custos, expandir a capacidade produtiva global para 6 milhões de veículos por ano e ampliar a capacidade produtiva nos mercados emergentes não asiáticos. Simultaneamente, o plano promoveu também uma mudança na estratégia de produtos da montadora, que passou, assim, a enfatizar a regionalização do desenvolvimento dos novos modelos. Como resultado desta mudança na estratégia de produtos, o Corolla, que era originalmente produzido em uma única versão, passou a ser fabricado em três versões diferentes: a norte-americana, a européia e a versão japonesa, com base na qual são desenvolvidas as variantes para os mercados em desenvolvimento (Fujimoto, $1997 \mathrm{e}$ 1999; Carvalho, 2003).

Em resposta à contínua tendência à 'nichificação' da demanda interna e à intensidade dos programas de introdução de novos modelos dos seus competidores, a Toyota colocou em andamento o mais intenso programa de desenvolvimento de novos produtos da indústria automobilística japonesa. E apesar de confrontada com alguns problemas no seu mercado doméstico nos anos recentes, a Toyota continua sendo uma das empresas líderes da indústria automobilística, tanto em termos da manufatura e da inovação produtiva, quanto em termos das novas tecnologias. Ao mesmo tempo, a Toyota tem procurado compatibilizar suas distintas capacidades, centralizando no Japão a produção voltada para os nichos de mercado - internos e externos - e deixando para os transplantes a produção em maior escala (Fujimoto, 1997 e 1999; EIU, 1998b).

A $\boldsymbol{V W}$. Incluindo a Audi, a Seat e a Skoda, a Volkswagen é o maior produtor europeu de autoveículos e, em 1999, foi o quinto maior fabricante mundial ao produzir 4,8 milhões de unidades ( $8,5 \%$ da produção global). Mas, apesar dos êxitos alcançados com a introdução dos novos modelos e dos progressos obtidos no seu processo de reestruturação, a lucratividade da montadora alemã ainda permanece relativamente baixa comparativamente aos resultados obtidos por outros produtores generalistas europeus e norte-americanos. O programa de reestruturação da Volkswagen - que tem sido a principal razão para o contínuo progresso da performance do grupo VW - pode ser caracterizado basicamente: a) pelo corte de custos, baseado principalmente na introdução da estratégia de racionalização das plataformas; b) pelo lançamento de novos modelos e pela reestruturação das subsidiárias Seat e Skoda. Além das estratégias mencionadas, o grupo VW está levando adiante um plano que tem por objetivo competir em todos os segmentos do mercado automobilístico (Bursa et al., 1998; Storey, 1998; Maxton; 1998).

O aspecto central do plano de atuação do grupo VW é a conhecida 'estratégia das plataformas'. Concebida em 1994, ela tinha como um de seus objetivos viabilizar a substituição das 16 plataformas de carros previamente existentes por apenas quatro novas plataformas, que seriam a base de todos os modelos a serem vendidos sob as marcas Volkswagen, Audi, Seat e Skoda. Também foi fundamental para o novo plano de atuação da VW a adoção das técnicas de manufatura flexível e da lean production. Além disto, a Volkswagen também introduziu pioneiramente o conceito de trabalho dos fornecedores diretamente na linha de montagem (Bursa et al., 1998; Storey, 1998; Maxton, 1998).

A Fiat. Em 1999, ao produzir 2,6 milhões de unidades, a Fiat foi a sétima maior produtora de automóveis do mundo e a quarta maior da Europa. Não obstante à significativa retomada das vendas em 1997, a montadora italiana tem convivido com a perspectiva de uma perda relativa de parcela de mercado tanto no âmbito doméstico quanto na União Européia. Numa tentativa de contrarrestar, ao menos em parte, estas perspectivas, a Fiat tem buscado, desde o início dos anos 90, uma maior diversificação geográfica de suas vendas, uma maior presença no segmento de veículos médios e também uma atualização da sua linha de modelos. Ainda com vistas a viabilizar o seu futuro, a Fiat Auto estabeleceu, em março 
de 2000, uma aliança defensiva estratégica com a GM. Com o acordo, fica praticamente eliminada a possibilidade de um take over hostil e mantêm-se as condições, pelo menos em princípio, de existência independente da Fiat Auto. Na pior das hipóteses, esta aliança permitirá ao grupo Fiat negociar um eventual merge com a própria GM (Bursa et al., 1998; Storey, 1998; EIU, 1998a; Maxton, 1998).

Lançado originalmente no Brasil em 1996 e relançado no final de 2000, o projeto 178 (a família Palio) tem tido um papel fundamental na estratégia de diversificação geográfica das vendas do grupo Fiat. Sendo já produzida em 8 países e montada em mais outros cinco, a linha de modelos desenvolvida para os mercados emergentes tem sido um grande sucesso da montadora italiana. Ainda quanto à estratégia de produtos, deve-se destacar que, como a maioria das montadoras européias, a Fiat tem também incorporado o conceito de plataformas. Entretanto, o grupo italiano tem adotado também um enfoque mais multi-regional na sua estratégia de produtos, o que o levou a desenvolver e introduzir uma plataforma inteiramente nova, concebida para atender às necessidades dos mercados emergentes: o projeto 178 (Bursa et al., 1998; Storey, 1998; EIU, 1998a).

Quando enfocada do ponto de vista das empresas e da competição nos principais mercados, a evolução recente da indústria automobilística tem revelado algumas surpresas. Talvez a surpresa mais notável tenha sido a reestruturação e o dinamismo da indústria automobilística norte-americana, explicados em grande medida pela forte expansão econômica e pelo notável crescimento do segmento dos ligths-trucks. No plano das empresas, a novidade foi a rapidez com que os indicadores de eficiência relativa têm mostrado uma diminuição dos gaps de produtividade e qualidade entre as montadoras japonesas e as ocidentais, particularmente no caso das norte-americanas. Este avanço das montadoras ocidentais não foi, entretanto, suficiente para eliminar a maior eficiência das montadoras japonesas que seguem, assim, líderes no que tange aos processos de manufatura (Fujimoto e Takeishi, 2001; Maxton, 1998 e 2000; Carvalho, 2003).

No caso das montadoras norte-americanas, por exemplo, não resta dúvida de que seu processo doméstico de reestruturação foi relativamente bem sucedido. E se a situação das montadoras dos Estados Unidos - quando examinada de forma agregada e tendo em conta a totalidade do mercado de veículos de passageiros (carros e veículos comerciais leves) - parece relativamente boa, o mesmo não parece ocorrer, entretanto, quando se faz uma análise mais detalhada de cada uma delas, do seu desempenho recente e das suas perspectivas. O quadro que então emerge mostra-se razoavelmente menos otimista. De fato, quando examinadas individualmente, duas delas - a
GM e a antiga Chrysler - revelam um desempenho recente e perspectivas não muito sólidas. Apenas a Ford parece apresentar uma situação mais consistente (Maxton, 2000; Olmos, 2005).

Já a participação dos produtores japoneses no segmento de mercado de automóveis dos E.U.A. tem sido bastante estável, oscilando em torno de 30\% desde 1991. Em 1997, as montadoras japonesas ultrapassaram, pela primeira vez, a marca de $31 \%$ e a Toyota e a Honda tornaram-se respectivamente a terceira e a quarta no segmento de mercado norte-americano de automóveis. Por outro lado, e embora venham sofrendo com a forte e longa crise em seu mercado doméstico e tenham também sido impactadas com a valorização do iene no triênio 1994/96, a Toyota e a Honda - as montadoras japonesas mais bem sucedidas nos E.U.A. - têm conseguido expandir paulatinamente as suas respectivas participações tanto no segmento de automóveis quanto no de veículos comerciais leves do mercado norte-americano (Maxton, 2000; JAT, 30/04/2000; Fujimoto e Takeishi, 2001).

Depois de quase 40 anos de crescimento ininterrupto, a indústria automobilística japonesa vem enfrentando um longo período de crise. E tudo leva a crer também que a atual recessão da indústria automobilística nipônica assinale a transição da chamada 'era de crescimento contínuo' para um novo período caracterizado pela flutuação do volume de produção doméstico. Não obstante a relativa perda de dinamismo da demanda interna, a competição na indústria automobilística japonesa segue sendo muito intensa e caracterizada por um bastante agressivo 'new product-oriented market environment' (Fujimoto, $1997 \mathrm{e}$ 1999; Maxton 2000; Fujimoto e Takeishi, 2001).

E a Toyota continua sendo a maior montadora japonesa, muito embora a sua participação no mercado tenha caído de 44\% em 1987 para 27,8\% em 1998. Sem ter a sua liderança diretamente ameaçada, uma vez que a Nissan também tem perdido parcela de mercado, a Toyota tem dado mostras de que pretende recuperar pelo menos parte do terreno perdido. De fato, foi a Nissan a mais impactada pelo notável desempenho recente da Honda que, tendo elevado significativamente a sua participação no mercado doméstico, passou a ocupar a segunda posição no ranking da indústria automobilística japonesa (EIU, 1999; Maxton, 2000; Fujimoto e Takeishi, 2001).

Os dados referentes à evolução recente do mercado nipônico revelam que a perda de participação relativa das maiores montadoras japonesas e a consequiente desconcentração do seu mercado doméstico resultou, principalmente, da expansão das montadoras menores. O ponto a destacar aqui é que só têm ganhado terreno no mercado japonês de automóveis as empresas que têm implementado um agressivo e bastante reativo programa de desenvolvimento de novos produtos e que têm sabido aproveitar 
também a forte tendência à 'nichificação', que vem crescentemente caracterizando a evolução daquela indústria (EIU, 1999; Maxton, 1998 e 2000; Fujimoto e Takeishi, 2001).

Na Europa Ocidental, o grupo VW (que inclui a Audi, a Seat e a Skoda) tem se mantido folgadamente à frente das rivais mais diretas. Sem uma ameaça imediata e contando com uma linha de modelos inovativa e stylish, a única meta ainda não lograda pela VW é a obtenção de níveis de lucratividade que satisfaçam aos seus acionistas e aos analistas em geral. De fato, apesar de bastante competitiva em termos de produtos, a VW ainda não conseguiu se equiparar em termos de custos produtivos às montadoras generalistas mais eficientes. $\mathrm{O}$ desempenho recente mais surpreendente no mercado europeu de automóveis tem sido o das montadoras francesas. Primeiro, foi à vez da Renault que, em razão da sua aliança com a japonesa Nissan, saltou da sexta para a segunda posição no ranking regional em poucos anos. Mais recente e, talvez ainda mais surpreendente, foi o caso da vigorosa ascensão da PSA (Peugeot Citroen). Com a expansão simultânea de suas duas marcas Peugeot e Citroën, a francesa PSA atingiu, em 2001, a segunda posição no ranking europeu ocidental das montadoras de automóveis (Maxton, 1998 e 2000; Rhys, 2001).

Dentre as montadoras de origem européia, a situação do grupo Fiat parece ser a mais vulnerável. Mais dependente do seu mercado nacional do que qualquer outra montadora européia, a Fiat não tem sido capaz de impedir a queda de sua participação relativa desde 1998. O término em 1999 das restrições às importações dos modelos japoneses e coreanos e a maior agressividade da VW deverão tornar ainda mais competitivos, na Itália e na Europa em geral, os segmentos de mercado A e B, que são vitais para a Fiat. Por outro lado, dadas as previsões pouco otimistas quanto ao comportamento da demanda por carros no mercado italiano no futuro próximo e as notícias sobre o desempenho financeiro negativo da Fiat em 2001, crescem os rumores de que a aliança entre a montadora italiana e a GM, realizada em 2000, venha a se converter numa verdadeira aquisição (Maxton, 1998 e 2000; Rhys, 2001; Feast, 2002).

A participação global das montadoras japonesas no mercado europeu de automóveis tem sido relativamente estável nos anos recentes. Em razão da ampliação dos transplantes em operação na União Européia e do término, em 1999, dos acordos de restrição voluntários (vers), espera-se uma expansão mais acentuada da participação das montadoras japonesas nos mercados europeus em geral e, em particular, nos mercados da França e da Itália (Maxton, 1998 e 2000; Rhys, 2001; Feast, 2002).

Já as duas montadoras norte-americanas têm apresentado um desempenho decepcionante nos mercados europeus nos últimos anos. Depois de um desempenho promissor na primeira metade da década, a GM não tem conseguido, desde 1995, evitar a diminuição contínua de sua parcela de mercado. E segundo as informações disponíveis, as perspectivas da GM européia para os próximos anos não parecem muito distintas do seu desempenho recente. Depois de manter uma estável participação no mercado europeu de automóveis entre 1990 e 1997, a Ford européia não tem conseguido, desde então, um desempenho tão regular - que só não foi ainda mais problemático em razão das recentes aquisições. Mas, apesar dos recentes lançamentos e/ou dos facelifts de vários modelos, as perspectivas para a Ford européia para o futuro próximo, segundo vários analistas, não parecem também muito promissoras (Maxton, 2000; Rhys, 2001; Feast, 2002).

\section{Estratégias competitivas recentes das principais montadoras da indústria automobilística no Brasil}

A análise da evolução recente e das estratégias competitivas implementadas pelas principais montadoras da indústria automobilística no Brasil não deve ser feita sem levar em conta o contexto de reestruturação, integração e modernização (associado em boa medida à globalização do setor automotivo) que marcou este setor da indústria brasileira, particularmente na segunda metade dos anos 90. Não se deve, por outro lado, esquecer que este processo teve, entretanto, a sua dinâmica determinada em grande medida pela evolução do próprio mercado local, pelo processo de integração regional e pela política econômica nacional. Com particular destaque, neste último caso, para a criação dos incentivos fiscais aos chamados carros 'populares', que têm desempenhado um papel crucial nas vendas internas nos anos recentes (Sarti, 2002; Carvalho, 2003).

No caso dos distintos comportamentos adotados pelas filiais brasileiras das montadoras internacionais parece haver quatro determinantes fundamentais: 1) a importância relativa da filial local (e do respectivo mercado local e/ou regional) para cada montadora; 2) as distintas capacitações acumuladas internamente em termos, por exemplo, do desenvolvimento local de produtos, etc.; 3) o estágio de implementação do respectivo processo interno de globalização/integração; e 4) as respectivas estratégias competitivas - de produção, de investimentos, de produtos, de P\&D, etc. - de cada montadora (Carvalho, 2003).

A Fiat no Brasil. Tendo sido a grande beneficiária do crescimento do mercado interno nos anos 90, a Fiat soube se aproveitar da forte expansão do segmento de carros de pequeno porte que resultou, principalmente, da introdução de estímulos à produção de veículos populares em 1993. Segundo as informações disponíveis, os investimentos realizados pela Fiat no Brasil, no período de 
1995 a 2000, teriam sido da ordem de US\$ 3,0 bilhões. Estes investimentos foram destinados ao lançamento do projeto 178 e de seus vários modelos; à ampliação da capacidade produtiva de Betim; às novas plantas de veículos comerciais leves e de caminhões; à introdução dos novos modelos Bravo/Marea e à implantação da nova linha de motores (Fire). A Fiat está atualmente disputando, com a GM, a posição de segundo maior produtor de veículos do país. Em 2000 e 2001, a produção da montadora italiana no Brasil foi de 433,7 e 436,6 mil veículos respectivamente (Kolodziejski, 1998; Bursa et al., 1998; Quadros Carvalho et al., 2000).

Depois de acumular experiência a partir da segunda metade dos anos 70, a Fiat do Brasil desenvolveu o Uno Mille em 1990. Adaptado pela engenharia local, o Uno Mille foi o primeiro automóvel equipado com um motor de 1.000 c.c. lançado no mercado brasileiro. Seguiu-se, em 1991, a introdução do Tempra saloon. Em novembro de 1995, o Fiat Tipo começou a ser produzido localmente na linha de produção do Tempra. Em abril de 1996 a Fiat lançou, a partir do Brasil, o seu projeto 178 - uma linha de modelos desenvolvida especificamente para atender às necessidades dos mercados emergentes e ser equipada com motores de baixa potência. Resultado de um esforço conjunto entre a matriz e a filial brasileira, o desenvolvimento do Palio (projeto 178) contou com uma significativa participação da engenharia local. Foram lançados sucessivamente os modelos Palio hatchba$c k$ de três e cinco portas e as versões station wagon, van e pickup. Em outubro de 2000, a Fiat fez a apresentação mundial da segunda geração da família Palio, reestilizada na forma, na motorização e na tecnologia embarcada. Em 2002 a montadora de Turim lançou no Brasil o Fiat Stilo (modelo de tamanho médio), o primeiro veículo da montadora italiana a utilizar um motor GM, produzido pela joint-venture que resultou da sua recente associação com a maior fabricante norte-americana de autoveículos (Kolodziejski, 1998; Quadros Carvalho et al., 2000; Consoni e Quadros, 2001 e 2002; Fiat, 2002).

A $\boldsymbol{V W}$ no Brasil. Os investimentos da Volkswagen no Brasil, no período de 1996 a 2000, foram estimados em US\$ 2,8 bilhões. O programa de investimento incluiu a instalação da planta de caminhões e ônibus em Resende (RJ) em 1995; a construção de uma nova planta de motores em São Carlos (SP) em 1996; a instalação de uma nova planta de montagem de automóveis em São José dos Pinhais (PR). Mais recentemente, a VW anunciou planos adicionais de investimento da ordem de US $\$ 3,0$ bilhões para um período de cinco anos, que resultariam numa completa reestruturação da unidade de São Bernardo, no lançamento do novo modelo PQ-24 (o Polo) e na modernização da unidade de Taubaté. Depois de ter sido por décadas o maior fabricante de veículos do Brasil, a VW tem mantido nos últimos anos uma intensa disputa pela liderança do mercado brasileiro de veículos leves com a Fiat e mais recentemente com a GM (Kolodziejski, 1998; Viladorga, 1999; GM, 2002).

Até recentemente, a VW vinha mantendo no Brasil a tradição de desenvolver modelos específicos para o mercado doméstico, tendo já desenvolvido localmente um carro esportivo em 1972, a Brasília hatchback em 1973 e as três gerações do Gol - introduzido em 1981 e remodelado sucessivamente em 1993 e 1999. Não obstante o grande sucesso, a família Gol tem grandes chances de ser o último modelo desenvolvido especificamente para as necessidades nacionais e a não compartilhar a sua plataforma com nenhum outro modelo da montadora. De fato, a nova estratégia de redução do número de plataformas, que tem sido adotada mundialmente pela VW, não é, em tese, compatível com a manutenção da estratégia de desenvolvimento local de modelos. Ocorre que o PQ-24 (o Polo) - o carro pequeno que a VW desenvolveu com base na plataforma do Polo europeu, para ser lançado na Europa e no Brasil, e que seria também o substituto natural do Gol - revelou-se mais caro do que as previsões iniciais, tendo sido posicionado, em termos de preço, entre os segmentos do Gol e do Golf. Mais recentemente, a VW anunciou para 2004 o lançamento de um novo modelo da família Polo. Conhecido apenas como projeto Tupy (Fox), o novo carro será lançado com o objetivo de se constituir no substituto do Gol (Kolodziejski, 1998; Bursa et al., 1998; Viladorga, 1999; Karan, 2002; Consoni e Quadros, 2001 e 2002).

GM no Brasil. Estima-se que durante o período de 1995 a 1999 a GM tenha investido cerca de US\$ 2,8 bilhões no Brasil. Estes investimentos foram aplicados nas plantas existentes, na nova planta de Gravataí (RS) e no lançamento de novos modelos de veículos leves e de caminhões. Em meados de 2000 a montadora norte-americana informou que planejava investir mais US\$ 1,5 bilhão, até 2003, na modernização das suas unidades industriais localizadas em São Paulo e no lançamento de novos produtos (Kolodziejski, 1998; Bursa et al., 1998; Zafira, 2000).

Nos anos 90, a GM do Brasil adotou uma estratégia de produtos agressiva, que resultou no lançamento de praticamente um novo modelo por ano. Por exemplo, em 1993 e 1994, foram lançados o Vectra e o Corsa hatchback, respectivamente. Em 2000, a maior montadora mundial relançou as novas versões do Astra e do Vectra e introduziu o Celta - o novo subcompacto, produzido em sua nova planta de Gravataí e projetado especificamente para mercados de terceiro mundo. Em 2001, a GM introduziu no mercado brasileiro a Zafira, uma mini van baseada na plataforma do Astra. Finalmente, em 2002, foram lançados novas versões do Corsa hatch e sedan e o monovo- 
lume Meriva. Em 2000 e especialmente em 2001, a GM superou a produção da Fiat ficando em segundo lugar na indústria automobilística brasileira, com respectivamente $27,4 \%$ (438 mil) e $29,8 \%$ (410 mil) do total de veículos leves fabricados no país (Kolodziejski, 1998; Bursa et al., 1998; Consoni e Quadros, 2001 e 2002; Ecosport, 2002).

A Ford no Brasil. De acordo com os dados disponíveis, os investimentos feitos pela Ford no Brasil entre 1995 e 1999 foram de cerca de US\$ 2,5 bilhões. As estimativas de investimentos para a instalação da nova planta de montagem de veículos de Camaçarí (BA), inaugurada em 2002, giram entre US\$1,2 e 1,6 bilhão. A unidade da Bahia será, a partir de 2003, a base brasileira de produção da linha de compactos do novo Fiesta. Com este novo modelo, a empresa espera alavancar a sua participação no mercado doméstico do Brasil e também ampliar a suas exportações. As informações disponíveis dão conta de que, com o novo Fiesta, a participação da Ford no mercado brasileiro de veículos leves teria saltado de $6,6 \%$ em agosto de 2001 para 11,3\% em agosto último (Kolodziejski, 1998; Bursa et al., 1998; EIU, 1997).

Em 1983, a Ford lançou no mercado brasileiro o seu modelo médio, o Escort, que viria a ser o principal produto da montadora norte-americana durante a existência da Autolatina (1987 a 1996). Em 1995, já na fase de dissolução da Autolatina, a planta de São Bernardo foi mais uma vez remodelada amplamente para viabilizar o lançamento do Fiesta, o novo compacto da montadora norte-americana. Lançado em 1996, o Fiesta marcou, juntamente com a dissolução da Autolatina em dezembro do mesmo ano, a retomada do interesse e dos investimentos da Ford pela filial e pelo mercado brasileiros. A introdução da versão brasileira do Fiesta demonstrou uma mudança de estratégia da Ford, que passou, assim, a disputar mais diretamente o segmento dos 'carros populares'. Buscando reforçar a sua presença no segmento dos carros pequenos, a montadora introduziu em 1997 o Ford $\mathrm{Ka}$ - o primeiro modelo subcompacto (ou mini) produzido no Brasil. Em novembro de 2000, a Ford lançou no Brasil o Focus hatchback. Em 2002, a Ford lançou o novo Fiesta. Este novo Fiesta é a versão brasileira da nova tentativa de introduzir um 'carro mundial' por parte da montadora norte-americana (Kolodziejski, 1998; Consoni e Quadros, 2001 e 2002; Ecosport, 2002; Olmos, 2002b; Carvalho, 2003).

A Toyota no Brasil. Em 1998, quase quarenta anos depois de instalar uma planta em São Bernardo (SP), a Toyota inaugurou a sua segunda planta brasileira em Indaiatuba (SP). A nova unidade, de US\$ 150 milhões, foi projetada para produzir inicialmente 15 mil unidades/ano do sedan de tamanho médio Corolla. Embora os planos para o lançamento do segundo modelo tenham sido adiados, a montadora japonesa realizou investimentos adicionais de US\$ 300 milhões no biênio 2000/01, ampliando a capacidade produtiva do Corolla das iniciais $15 \mathrm{mil}$ para 45 mil unidades anuais (Kolodziejski, 1998; Olmos, 2002a).

Ainda que tenha melhorado no último ano, o desempenho da maior montadora japonesa no mercado brasileiro tem sido apenas moderado, se comparado, por exemplo, ao desempenho da Renault ou mesmo da Honda. Este desempenho modesto da Toyota no Brasil deve-se principalmente à sua ausência nos segmentos de maior demanda do mercado brasileiro. Esta situação não deve mudar muito, mesmo com o lançamento, em 2002, da nova geração do Corolla. Por outro lado, a maior montadora japonesa continua cautelosa quanto a uma eventual entrada no segmento de carros compactos do mercado brasileiro (Moreira, 2002; Ecosport, 2002).

\section{Considerações sobre as estratégias de produtos, de P\&D e o desempenho das montadoras no mercado brasileiro}

A análise das recentes estratégias de produtos e de $\mathrm{P} \& \mathrm{D}$ das cinco principais montadoras instaladas no Brasil - GM, Ford, VW, Fiat e Toyota - parece indicar a existência de evidências de uma forte associação, em termos gerais, entre as estratégias globais de produtos e a atuação local das filiais das montadoras, tanto em relação à intensidade quanto à natureza de sua participação no desenvolvimento de produtos (Quadros Carvalho et al., 2000; Consoni e Quadros, 2001 e 2002).

Desta forma, as montadoras que têm adotado estratégias de modelos com características de globalização - envolvendo tanto a modificação de plataformas globais para a adaptação local como o desenvolvimento de plataformas para o terceiro mundo - como, por exemplo, a GM e a Fiat, têm também apresentado uma expansão de suas infraestruturas locais de P\&D (Quadros Carvalho et al., 2000).

Estes fatos, importantes por si sós, parecem ganhar ainda mais relevância quando se leva em conta o desempenho de vendas dos diversos modelos ao se procurar analisar a evolução recente das montadoras na indústria automobilística brasileira. $\mathrm{O}$ exame das Tabelas 1 e 2 do Anexo parece dar forte respaldo ao argumento de que o êxito recente no mercado brasileiro de automóveis está associado à introdução de modelos que apresentem marcada adaptação às características e aos gostos locais, quer seja por meio do desenvolvimento de plataformas para países em desenvolvimento e/ou locais - casos das famílias Gol (VW) e Palio (Fiat) e do modelo Celta (GM) -, quer seja por meio de derivativos específicos e/ou fortemente adaptados - casos do Uno Mille de 1.000 c.c. da Fiat, das versões sedan, station wagon, pickup e da Meriva do Corsa e também da versão de quatro portas do Astra da GM (Carvalho, 2003). 
De fato, a análise das referidas tabelas revela que os cinco modelos mais vendidos - tanto entre os veículos de 1.000 c.c. como em geral (VW Gol, Fiat Palio, Fiat Uno, GM Celta e Corsa sedan) - são exemplos de estratégias de produtos que dão boa margem de adaptação às demandas regionais e/ou locais e que têm sido genericamente qualificadas como globalização (Ruigrock e van Tulder, 1995; Carvalho, 2003). Por outro lado, as mencionadas tabelas também revelam que os modelos característicos da estratégia de globalização adotada pela Ford (e mais recentemente pela VW), tais como o $\mathrm{Ka}$ e, em grande medida, o Fiesta, não têm sido muito bem-sucedidos no mercado brasileiro. De fato, o Ford Fiesta foi apenas o sétimo veículo de 1.000 cilindradas mais vendido no Brasil em 2001 e o sexto em 2002 e 2003, ficando em ambos os casos atrás do Celta da GM. O Ford Ka, por sua vez, foi o décimo segundo e o décimo do ranking dos mais vendidos respectivamente em 2001 e 2003 (Carvalho, 2003).

Da mesma forma, são as empresas que têm implementado estratégias de forte adaptação dos produtos aos mercados locais - como a Fiat e a GM (e a VW até no passado recente) - as que têm obtido também os melhores resultados no segmento dos chamados 'carros populares', com consequiências importantes para a participação no mercado doméstico total, dada a grande parcela representada por este segmento (Carvalho, 2003).

Com uma aposta mais radical, há o exemplo da Fiat, que claramente buscou uma estratégia "focada nos veículos de pequeno porte e baixa motorização" (Quadros Carvalho et al., 1997), pela qual os veículos de 1.000 cilindradas responderam por 62,8 da produção total da montadora em 1998 (Carvalho et al., 2001). Esta ênfase no segmento de veículos de pequeno porte é certamente coerente com a estratégia perseguida pela montadora italiana desde sua entrada no Brasil e também é consistente com a recentemente implementada estratégia de plataforma regional (Quadros Carvalho et al., 2000; Bursa et al., 1998).

Até mesmo a GM - caracterizada por uma maior diversificação do mix de produtos e por dar menos ênfase tradicionalmente ao segmento de veículos pequenos - não deixou, entretanto, de dar atenção ao segmento dos 'carros populares', como atestam os lançamentos bem sucedidos das várias versões do Corsa nos anos 90 e, mais recentemente, do Celta. De fato, em 1998 a participação dos veículos de 1.000 c.c. na produção total da GM foi de 45,5\% (Carvalho et al., 2001; Carvalho, 2003).

Até certo ponto surpreendente e relativamente tímida tem sido a postura da VW em relação ao segmento de 'carros populares' - sobretudo quando levamos em conta sua tradição de produzir veículos de pequeno porte no Brasil. O fato é que, apesar de que "a remodela- ção do Gol parece ter levado em conta a necessidade de uma carroceria mais leve, que pudesse receber [um] motor menos potente" (Quadros Carvalho et al., 1997), as vendas de carros populares da VW - que em 1994 eram de cerca de $40 \%$ - só ultrapassaram a marca de 50\% (55,6 para ser exato) da sua produção total em 1998 (Carvalho, 2003).

O caso da VW é bastante peculiar e um tanto paradoxal. Por um lado, a nova estratégia de redução de plataformas adotada mundialmente pela VW não parece compatível com a manutenção da estratégia de desenvolvimento de modelos locais, que foi sabidamente uma das características fundamentais da história de sucesso da montadora alemã no mercado brasileiro. Por outro, a montadora tem se visto 'forçada' a adiar a anunciada substituição do modelo que foi seu campeão de vendas por mais de uma década (ver novamente o item IV e Carvalho, 2003). Igualmente ambígua e incerta tem sido a postura da VW quanto ao futuro da sua atual equipe de desenvolvimento de produtos e processos e das competências adquiridas ao longo do tempo com o desenvolvimento de modelos para o mercado local (Quadros Carvalho et al., 2000; Consoni e Quadros, 2001 e 2002).

Como a Ford abandonou radical e completamente a sua velha estratégia de modelos regionais com a implementação do Ford 2000, a sua equipe local de desenvolvimento de produtos e processos - que no passado já fora uma das maiores unidades de engenharia de produtos da América Latina - tem sido, desde então, continuamente reduzida (Quadros Carvalho et al., 1997 e 2000).

Entretanto, no segmento dos 'carros populares' a Ford tem sido, desde meados dos anos 90 , relativamente mais agressiva. Depois de um relativo desinteresse por suas atividades no Brasil, que se traduziu na integração subordinada à VW no âmbito da Autolatina, a montadora norte-americana reviu sua postura. Em 1996 e 1997 a Ford lançou sucessivamente as versões brasileiras do Fiesta e do Ka (ambos com versões de 1.000 c.c.), promovendo uma importante mudança na sua estratégia de produtos que, desde então, passou a dar prioridade ao segmento dos "carros populares". Em consequiência disso, a participação dos veículos de 1.000 cilindradas na produção total da Ford atingiu, em 1998, a elevada cifra de 79,4\% (Carvalho et al., 2001).

Mas nem mesmo um esforço concentrado no segmento de veículos de 1.000 cilindradas -nenhuma outra montadora, nem mesmo a Fiat (com 62,8\%), é tão fortemente dependente dele -tem sido suficiente para permitir à Ford recuperar o terreno perdido. Este último fato, que provavelmente não é mera coincidência, e o exemplo, até certo ponto oposto, da VW parecem reforçar o argumento anterior de que o êxito no mercado brasileiro de automóveis, incluindo-se, é claro, o segmento de 'populares', tem 
exigido mais do que apenas novos modelos: tem exigido também modelos que se caracterizem por um elevado grau de adaptação às especificidades e aos gostos locais. Atributos que os modelos concebidos sob a lógica da assim chamada estratégia de globalização de produtos não têm sido capazes de incorporar adequadamente, a julgar pela evolução recente do mercado brasileiro de automóveis (Carvalho, 2003).

A Ford vem tentando retomar o espaço perdido nos últimos anos com base principalmente no crescimento das vendas decorrentes do lançamento em 2002 do novo Fiesta - a nova geração do seu carro popular originalmente lançado no Brasil em 1996 -, por meio de um forte esforço de marketing e de vendas e contando ainda com o reforço do Focus, do já relativamente desatualizado Ka e dos antigos Escort e Fiesta (que ainda não saíram de linha). O êxito de vendas do novo Fiesta parece ter dado novo alento às expectativas quanto ao futuro da montadora no Brasil e diminuído os temores em relação à sua eventual saída do mercado nacional - pelo menos temporariamente (Carvalho et al., 2001; Valor, 28/10/02; Carvalho, 2003).

\section{Conclusão}

Conforme já destacado anteriormente, o exame comparativo das estratégias de produtos e de $\mathrm{P} \& \mathrm{D}$ das cinco principais montadoras de automóveis instaladas no Brasil - GM, Ford, VW, Fiat e Toyota - parece indicar que há, por um lado, uma clara relação entre as referidas estratégias adotadas pelas filiais locais e as correspondentes estratégias implementadas pelas respectivas matrizes no âmbito internacional e, por outro, evidências de uma forte associação entre o êxito no mercado brasileiro de automóveis e a introdução de modelos que apresentam marcada adaptação às características e aos gostos locais. Isto é, têm sido as empresas que têm optado pelo desenvolvimento de plataformas específicas para os países em desenvolvimento e/ou mercados locais - casos das famílias Palio (Fiat) e Gol (VW) e do modelo Celta (GM) - e de derivativos específicos e/ou fortemente adaptados - casos do Uno Mille (Fiat), das versões sedan, station wagon, pickup do Corsa e da Meriva (GM) - as que têm obtido os melhores resultados no mercado brasileiro de automóveis nos anos recentes.

\section{Anexo estatístico}

Tabela 1. Os 15 Automóveis mais vendidos no atacado em 2001, 2002 e 2003.

\begin{tabular}{|c|c|c|c|c|c|c|c|c|c|}
\hline \multirow[t]{2}{*}{ Modelo } & \multicolumn{3}{|c|}{2001} & \multicolumn{3}{|c|}{2002} & \multicolumn{3}{|c|}{2003} \\
\hline & Ranking & $\begin{array}{c}\text { Vendas } \\
\text { (unidade) }\end{array}$ & $\begin{array}{c}\text { Mercado } \\
(\%)\end{array}$ & Ranking & $\begin{array}{c}\text { Vendas } \\
\text { (unidade) }\end{array}$ & $\begin{array}{c}\text { Mercado } \\
(\%)\end{array}$ & Ranking & $\begin{array}{c}\text { Vendas } \\
\text { (unidade) }\end{array}$ & $\begin{array}{c}\text { Mercado } \\
(\%) \\
\end{array}$ \\
\hline VW Gol & 1 & 265.898 & 20,5 & 1 & 208.657 & 17,93 & 1 & 177.614 & 15,9 \\
\hline Fiat Palio & 2 & 163.706 & 12,6 & 2 & 118.949 & 10,22 & 3 & 111.704 & 10,0 \\
\hline Fiat Uno & 3 & 114.416 & 8,8 & 5 & 93.306 & 8,01 & 4 & 92.075 & 8,2 \\
\hline GM Celta (1.0) & 4 & 90.159 & 7,0 & 3 & 110.573 & 9,50 & 2 & 113.469 & 10,1 \\
\hline $\begin{array}{l}\text { GM Corsa } \\
\text { Sedan }(1.0+0)\end{array}$ & 5 & 83.526 & 6,4 & 4 & 69.603 & 5,98 & 5 & 85.418 & 7,6 \\
\hline $\begin{array}{l}\text { GM Corsa } \\
\text { Hatch }\end{array}$ & 6 & 52.123 & 4,0 & 8 & 28.180 & 2,42 & 9 & 27.631 & 2,5 \\
\hline Ford Fiesta & 7 & 42.559 & 3,3 & 6 & 58.918 & 5,06 & 6 & 63.393 & 5,7 \\
\hline $\begin{array}{l}\text { Fiat Palio } \\
\text { Weekend }\end{array}$ & 8 & 37.303 & 2,9 & 10 & 21.619 & 1,85 & 11 & 18.653 & 1,7 \\
\hline Fiat Siena & 9 & 33.942 & 2,6 & 9 & 22.984 & 1,97 & 7 & 35.359 & 3,2 \\
\hline VW Golf & 10 & 32.627 & 2,5 & - & 27.974 & 2,40 & - & 12.927 & 1,2 \\
\hline $\begin{array}{l}\text { Renault Clio } \\
\text { Hatch }\end{array}$ & 11 & 27.021 & 2,1 & 13 & 25.136 & 2,16 & 10 & 24.006 & 2,1 \\
\hline $\begin{array}{l}\text { Peugeot } 206 \\
(1.0 \text { e } 0)\end{array}$ & 12 & 26.911 & 2,1 & 7 & 28.290 & 2,43 & 8 & 33.377 & 3,0 \\
\hline VW Parati & 13 & 24.697 & 1,9 & - & 15.102 & 1,29 & - & 10.585 & 0,9 \\
\hline $\begin{array}{l}\text { GM Astra } \\
\text { Hatch }\end{array}$ & 14 & 21.677 & 1,7 & 19 & 16.208 & 1,39 & 13 & 16.375 & 1,5 \\
\hline Honda Civic & 15 & 21.399 & 1,7 & 15 & 20.712 & 1,77 & 12 & 16.377 & 1,5 \\
\hline
\end{tabular}

Fonte: Automotive business (2004); ANFAVEA (2004). 
Tabela 2. Vendas Internas de automóveis de até 1.000 cilindradas de 2000 a 2003.

\begin{tabular}{|c|c|c|c|c|c|c|c|c|c|c|c|}
\hline Modelos & $\begin{array}{r}20 \\
\text { Vendas } \\
\text { (unid.) }\end{array}$ & $\begin{array}{l}\text { Mercado } \\
\text { Mer } \\
(\%)\end{array}$ & $\begin{array}{l}\text { Vendas } \\
\text { (unid.) }\end{array}$ & $\begin{array}{c}2001 \\
\text { Mercado } \\
(\%)\end{array}$ & Ranking & $\begin{array}{l}\text { Vendas } \\
\text { (unid.) }\end{array}$ & $\begin{array}{c}2002 \\
\text { Mercado } \\
(\%) \\
\end{array}$ & Ranking & $\begin{array}{l}\text { Vendas } \\
\text { (unid.) }\end{array}$ & $\begin{array}{r}2003 \\
\text { Merca } \\
(\%)\end{array}$ & anking \\
\hline VW Gol & 231.532 & 29,6 & 258.371 & 28,2 & 1 & 186.091 & 22,7 & 1 & 137.804 & 19,5 & 1 \\
\hline Fiat Palio & 136.758 & 17,5 & 154.734 & 16,5 & 2 & 118.949 & 14,5 & 2 & 100.938 & 14,3 & 2 \\
\hline Fiat Uno & 103.142 & 13,3 & 111.416 & 12,4 & 3 & 93.306 & 11,4 & 4 & 92.075 & 13,0 & 4 \\
\hline $\begin{array}{l}\text { GM Corsa } \\
\text { Sedan }\end{array}$ & 78.822 & 10,1 & 70.065 & 8,5 & 5 & 79.603 & 9,7 & 5 & 68.281 & 9,7 & 5 \\
\hline $\begin{array}{l}\text { GM Corsa } \\
\text { Hatch }\end{array}$ & 73.150 & 9,4 & 48.820 & 5,1 & 6 & 28.180 & 3,4 & 8 & 22.746 & 3,2 & 9 \\
\hline Ford Fiesta & 39.949 & 5,1 & 41.885 & 4,6 & 7 & 58.918 & 7,2 & 6 & 56.583 & 8,0 & 6 \\
\hline Ford $\mathrm{Ka}$ & 24.641 & 3,2 & 14.480 & 1,5 & 12 & 18.356 & 2,2 & 11 & 22.106 & 3,1 & 10 \\
\hline GM Celta & 23.251 & 3 & 90.159 & 9,8 & 4 & 110.573 & 13,5 & 3 & 109.748 & 15,5 & 3 \\
\hline Renault Clio & 20.330 & 2,6 & 23.763 & 2,6 & 9 & 23.528 & 2,9 & 9 & 21.715 & 3,1 & 11 \\
\hline Fiat Siena & 10.288 & 1,3 & 25.740 & 2,8 & 8 & 23.112 & 2,8 & 10 & 27.407 & 3,9 & 7 \\
\hline VW Parati & 9.161 & 1,2 & 13.280 & 1,4 & 13 & 11.688 & 1,4 & 13 & 2.662 & 0,4 & 13 \\
\hline $\begin{array}{l}\text { GM Corsa } \\
\text { Wagon }\end{array}$ & 7.659 & 1,0 & 4.385 & 0,5 & 15 & 313 & 0,0 & 15 & 2 & 0,0 & 15 \\
\hline $\begin{array}{l}\text { Fiat Palio } \\
\text { Weekend }\end{array}$ & 6.922 & 1,1 & 16.069 & 1,7 & 11 & 11.121 & 1,4 & 14 & 503 & 0,1 & 14 \\
\hline Peugeot 206 & - & - & 17.707 & 1,9 & 10 & 31.924 & 3,9 & 7 & 23.182 & 3,3 & 8 \\
\hline $\begin{array}{l}\text { Renault Clio } \\
\text { Sedan }\end{array}$ & - & - & 11.755 & 1,3 & 14 & 12.399 & 1,5 & 12 & 11.431 & 1,6 & 12 \\
\hline
\end{tabular}

*Em ordem decrescente de vendas e participação no mercado.

Fonte: Automotive Business, 2004.

\section{Referências Bibliográficas}

ASSOCIAÇÃO NACIONAL DOS FABRICANTES DE VEÍCULOS AUTOMOTORES (ANFAVEA). Estatísticas. Disponível em: <http://www.anfavea.com.br>. Acesso em: set 2004.

AUTOMOTIVEBUSINESS. Estatísticas. Disponível em: $<$ http://www.automotivebusiness.com.br $>$. Acesso em: nov. 2002.

AUTOMOTIVEBUSINESS. Estatísticas. Disponível em: $<$ http://www.automotivebusiness.com.br $>$. Acesso em: set. 2004.

BORDENAVE, G. Globalization at the heart of organization change: crisis and recovery at the Ford Motor Company. In: FREYSSENET, M.; MAIR, A.; SHIMIZU, K.; VOLPATO, G. (eds). One Best Way? Trajectories and Industrial Models of the World's Automobiles Producers. London: Oxford University Press, 1998. p. 365394.

BURSA, M.; HUNSTON, H.; LEWIS, A. WRIGHT, C. Transplant and Beyond: the internationalisation of the word's automotive manufacturers. London: Financial Times Automotive, 1998. p. 212.
CALMON, F. Setor automotivo ensaia retomada. Automotivebusiness, São Paulo. Disponível em: <http://www. automotivebusiness.com.br/fernando.htm $>$. Acesso em: 27 nov 2002.

CARVALHO, E. G. de; RACHID, A.; MARTINS, R. A. Estratégias empresariais e conduta tecnológica: indústria automobilística. Relatório Final FINEP/GEEINUNESP. Campinas, 2001.

CARVALHO, E. G. de. Globalização e estratégias competitivas na indústria automobilística: uma abordagem a partir das principais montadoras instaladas no Brasil. 2003. 274 f. Doutorado. (Doutorado em Economia) - Universidade de Campinas-UNICAMP, Campinas, 2003.

CONSONI, F. L.; QUADROS CARVALHO, R. Oportunidades e obstáculos para a criação de capacitações de desenvolvimento de produto na indústria automobilística: a experiência brasileira. In: CONGRESSO BRASILEIRO DE GESTÃO E DESENVOLVIMENTO DE PRODUTO, 3, 2001. Anais... Florianópolis, 2001.

CONSONI, F. L.; QUADROS CARVALHO, R. Desenvolvimento de produtos na indústria automobilística brasi- 
leira: perspectivas e obstáculos para a capacitação local. Revista de Administração Contemporânea, v. 6, n. 1, p. 39-62, 2002.

ECONOMIST INTELIGENCE UNIT. The global auto industry: in the aftermath of Daimlerchrysler. Motor Business International, London, $3^{\circ}$ quadrimestre. 1998a.

ECONOMIST INTELIGENCE UNIT. Japan's new model programmes: competition drives proliferation". Motor Business Japan. London, $1^{\circ}$ quadrimestre. 1998b

ECONOMIST INTELIGENCE UNIT. Japan's new model programmes: rationalisation and proliferation?. Motor Business Japan. London, $1^{\circ}$ quadrimestre. 1999.

ECONOMIST INTELIGENCE UNIT. The Automotive Sectors of South America and Mexico. London: The Economist Group, 1997.

ECOSPORT e Cargo Max Ton, os novos modelos dos 84 anos da Ford no Brasil. Automotive Business, 23 abril 2003. São Paulo. Disponível em: <http://www.automotivebusiness.com.br/ecosport.htm>. Acesso em: 27 nov 2002.

FEAST, R. Carmakers face growth problems in bigger EU. Automotive News Europe, Alemenha, 25 august 2002, Automotive news Europe. Disponível em: <http://europe.autonews.com/>. Acesso em: 29 agosto 2002.

FINE, C. H.; LAFRANCE, J. C.; HILLEBRAND, D. The U.S. automobile manufacturing industry. U.S. Departament of Commerce, Office of Technology Policy, 1996.

FIAT Stilo chega ao mercado para ser a nova referência dos carros médios. Infocarro, São Paulo, setembro 2002, Novidades. Disponível em: <http://.www.infocarro.com. br>. Acesso em: 19 abril 2005.

FLYNN, M. S. The General Motors trajectory strategic shift or tactical drift?. In: FREYSSENET, M.; MAIR, A.; SHIMIZU, K.; VOLPATO, G. One Best Way? Trajectories and Industrial Models of the World's Automobiles Producers. London: Oxford University Press, 1998. p. $179-210$.

FREYSSENET, M.; LUNG, Y. Between globalization and regionalization: what is the future of the automobile industry. In: GERPISA INTERNATIONAL COLLOQUIUM, 5, Paris, 1997. Actes... Paris: GERPISA, 1997.

FUJIMOTO, T. Capacity building and over-adaptation: a case of 'fat design' in the japonese auto industry. In: GERPISA INTERNATIONAL COLLOQUIUM, 5, Paris, 1997. Actes... Paris: GERPISA, 1997.

FUJIMOTO, T. The Evolution of a Manufacturing System at Toyota. New York: Oxford University Press, 1999.

FUJIMOTO, T.; TAKEISHI, A. Automobiles: strategy-ba- sed lean production system. Discussion Papers. Tokyo, 2001.

RHYS, G. Review of the global motor industry. Financial Times, London, 13 dezembro 2001, News \& Analysis/ Industries. Disponível em: <http://news.ft.com/>. Acesso em: 28 janeiro 2002.

GM encosta na Fiat: balanço parcial mostra boa disputa pela herança. Infocarro. São Paulo, outubro 2002, Notícias. Disponível em: <http://.www.infocarro.com.br>. Acesso em: 19 abril 2005.

HATZICHRONOGLOU, T. The globalisation of industry in the OECD countries. Working Papers. Paris, 1999.

HUMPHREY, J.; LECLER, Y.; SALERNO, M. S. Global Strategies and Local Realities: The Auto Industry in Emerging Markets. Basingstoke: Macmillan, 2000.

JAPAN AUTO TRENDS. Japanese auto manufacturers bullish for 2001. v. 5, n. 1, 2001. Disponível em: <http:// www.japanauto.com/library/jat/jat_v5n1.html>. Acesso em: março 2001.

KARAM, M. Volks prepara fábrica para novo carro. Valor Econômico, São Paulo, 30 outubro 2002, Seminários. Disponível em: <http://www.valoronline.com.br>. Acesso em: 01 jan. 2003.

KOLODZIEJSKI, J. (1998). Mercosur's automotive industry. London: Finacial Times Automotive, 1998.

MAXTON, G. P. Global car forecasts to 2005 - the outlook for world car sales. Disponível em: <http://justauto.com/F2/>. Acesso em: 2000.

MAXTON, G. P. World car forecasts: the outlook for sales, production and vehicles in use to 2005 . Research Report. London, 1998.

McALIDEN, S. P.; FEINSTEIN, A.; SMITH, B. C. Michigan automotive partnership research memoradum no.2. Report. Michigan, 2000.

MOREIRA, T. Toyota quer $10 \%$ do mercado brasileiro até 2010. Valor Econômico, São Paulo, 08 outubro 2002, Notícias. Disponível em: <http://www.valor.com.br/ veconomico/?show $=$ showNot $\& n=\& i d=1460228>$. Acesso em: 18 abril 2005.

OLMOS, M. Crise das americanas é uma bola de neve. Valor Econômico, São Paulo, 20 abr. 2005. Caderno B, p. 9.

OLMOS, M. Mercado externo é saída para unidade brasileira. Valor Econômico, São Paulo, 28 outubro 2002 b. Disponível em: <http://www.valor.com.br/veconomico/ ?show $=$ index \&mat $=1493541 \&$ edicao-461 $>$. Acesso em: 18 abril 2005.

OLMOS, M. Toyota adia o aumento da produção. Valor Econômico, São Paulo, 14 junho 2002a, Impresso, $1^{\circ}$ Cader- 
no. Disponível em: <http://www.valor.com.br/veconomico/caderno/?show $=$ index $\& n=\&$ mat $=1264325 \&$ edicao $>$. Acesso em: 18 abril 2005.

ORGANIZATION FOR ECONOMIC CO-OPERATION AND DEVELOPMENT. Measuring Globalisation: The Role of Multinationals in OECD Economies. Paris: OECD, $2001 \mathrm{~b}$.

PARTNERSHIP FOR A NEW GENERATION OF VEHICLES (PNGV). Review of the research program of the partnership for a new generation of vehicles: seventh report (2001). Disponível em: <http://www.nap.edu/ openbook/030907603X/html/R15.html>. Acesso em: 2001.

PRESENT and future automotive technologies. In: Personal Cars and China. Washington D.C.: The National Academics Press. cap. 04, 2003. p. 61-111. Disponível em: <http://www.nap.edu/books/03090908492X/html/ R1.html>. Acesso em 21/04/2005.

QUADROS CARVALHO, R.; QUEIROZ, S. R. R.; CONSONI, F. L.; COSTA, I; COSTA, J. P. da. Abertura comercial e mudança estrutural na indústria automobilística brasileira. Relatório (mimeo). Campinas, 1997.

QUADROS CARVALHO, R.; QUEIROZ, S. R. R.; HUMPHREY, J.; CONSONI, F. L.; COSTA, I.; FONSECA,
R. R. Globalização e Reestruturação da Cadeia Produtiva na Indústria automotiva: qual é o papel do Mercosul?. Relatório Final. Campinas, 2000.

RUIGROK, W.; VAN TULDER, R. The Logic of International Restructuring. London: Routledge, 1995.

SARTI, F. Cadeia: Automotiva. In: Estudos da competitividade de cadeias integradas no Brasil: impactos das zonas de livre comércio. Nota Técnica MIDC. Brasília, 2002.

STOREY, J. The world's car manufacturers: a strategic review of finance and operations. London: Financial Times Business Ltd, 1998.

STURGEON, T.; FLORIDA, R. The world that change the machine: globalization and jobs in the automotive industry. Final Report, IMVP, Massachusetts, 1999.

VICKERY, G. Globalisation in the automobile industry. In: Globalisation of Industry. Paris: OCDE, 1996.

VILADORGA, V. Concorrência força Volkswagen a apressar carro mundial. Gazeta Mercantil, São Paulo, 29 fevereiro 1999, Caderno C. Disponível em: <http://www. gazeta.com>. Acesso em: 19 janeiro 2000.

ZAFIRA, a minivan que trouxe US\$ 1,5 bi. O Estado de São Paulo, São Paulo, 20 julho, 2000. Disponível em: $<$ http://www.estado.com.br/>. Acesso em: 11 março 2001.

\title{
GLOBALIZATION AND COMPETITIVE STRATEGIES IN THE AUTOMOTIVE INDUSTRY: AN APPROACH FROM THE PESPECTIVE OF THE MAIN ASSEMBLERS IN BRAZIL
}

\begin{abstract}
This paper discusses several aspects of the international automotive industry, to wit, the process of globalization, the important role of new technologies in this industry, recent changes and main trends in competitive strategies, particularly those involving globalization and products, implemented by some of the main automakers around the world (GM, Ford, Toyota, VW, Fiat), and last but not least, international plans and Brazil's domestic market.
\end{abstract}

keywords: Brazil's automotive industry, globalization, new technologies in the automotive industry, competitive strategies, product strategies, $R \& D$. 